\title{
Evaluation of Activity Patterns in Quinpirole-Treated Rats
}

\author{
Carlos L. Paíno \\ Servicio de Neurobiología-Investigación, Hospital Ramón y Cajal, Instituto Ramón y Cajal de Investigaciones \\ Sanitarias (IRYCIS), Madrid, Spain \\ Email: carlos.paino@hrc.es
}

Received 16 May 2014; revised 22 June 2014; accepted 6 July 2014

Copyright (C) 2014 by author and Scientific Research Publishing Inc.

This work is licensed under the Creative Commons Attribution International License (CC BY).

http://creativecommons.org/licenses/by/4.0/

(c) (i) Open Access

\section{Abstract}

The present study aims to evaluate in rats the activity changes associated to treatments with D2-like receptor agonists using a simple behavioral procedure. Rats receiving a single dose of 1 $\mathrm{mg} / \mathrm{kg}$ quinpirole or vehicle were scored for 6 spontaneous behaviors at different post-injection times. In each time point, the animals were placed in testing cages for $12 \mathrm{~min}$ and video-recorded during the last $2 \mathrm{~min}$. The number of forelimb steps and the time spent sniffing were significantly increased by $15 \mathrm{~min}$ post-injection in the quinpirole group. Forelimb steps remained increased for at least $24 \mathrm{~h}$. Scores of time spent sniffing, as well as time inactive and number of hindlimb steps appeared greatly altered at 90 and $180 \mathrm{~min}$, but not at later time points. By $48 \mathrm{~h}$, no differences between control and quinpirole-treated rats were observed. In conclusion, the simple behavioral procedure here proposed-or adaptations of it-provides a sensitive test to evaluate the time course of the effects of D2-like receptor agonists on rat spontaneous activity. Additionally, this test takes into account context-dependent sensitization. It can be adapted to different treatment conditions. This methodology would be useful for the preclinical screening of D2-like receptor drugs, using reduced numbers of animals to test those doses and treatment schedules producing less side-effects.

\section{Keywords}

Behavioral Activity, D2-Like Receptor Agonist, Spontaneous Behavior, Stepping, Sniffing

\section{Introduction}

Dopaminergic drugs produce complex patterns of behavioral effects as a result of the diversity of nervous structures receiving dopamine input, the duality of dopamine receptors with opposed action and the existence of both 
presynaptic (which regulate dopamine synthesis and release [1]) and postsynaptic receptors with different affinity [2]. Furthermore, phenomena such as desensitization [3] or sensitization [4] [5] of dopamine receptors add additional uncertainty on the outcome of a given treatment. Even in controlled experimental conditions, a given dose of a dopaminergic drug may elicit biphasic patterns of behavioral activity [6] [7], different doses may produce opposite responses, and the effect of chronic treatments may differ from the effect of acute drug administration [8] [9].

The D2-like family of dopamine receptors (D2R) has been involved in several psychiatric conditions, like schizophrenia, bi polar disorder, compulsive-obsessive disorder, ADHD or a ddictions. When tested in rodents, selective D2R agonists like quinpirole, pramipexole or ropinirole have been shown to produce changes in basal activity and locomotion, stereotypies, context-dependent sensitization or compulsive checking behavior. Those behavioral outcomes can be considered as experimental indicators of the unwanted side-effects observed when D2R a gonists are used to treat di verse neurological c onditions, like P arkinson's di sease or restless legs s yndrome. Preclinical screening of new selective or partial agonists for neurological or psychiatric treatment would be expedited by the availability of simpler and faster animal behavioral tests. Here I present an easy, inexpensive and reproducible procedure to quantify the intensity and time c ourse of the pharmacological ef fects of D2R agonists on rat spontaneous behavior.

\section{Methods}

\subsection{Animals}

Adult male Sprague-Dawley rats weighing $250 \mathrm{~g}$ were used. The experimental procedures were approved by the Ramon y Cajal Hospital Animal Welfare Ethic Committee and followed the ethical guidelines of the Spanish legislation on "Protection of animals used for experimentation and other scientific goals" (RD 1201/2005). The rats were bred in the Ramón y Cajal Hospital animal premises, where fresh male breeders from Charles River (France) were introduced to the colony every 4 - 5 months. Relatively low numbers of experimental animals (10 rats per experimental group) were purposely used to demonstrate the sensitivity of the procedure. The animals were housed 2 per cage and maintained at $24^{\circ} \mathrm{C}$ room temperature under a 12 -h light/12-h dark schedule.

\subsection{Behaviors}

Based on previous observations of quinpirole-treated rats, six behaviors that appeared altered after drug administration were quantified as follows:

Sniffing: Time spent by the animal in active smelling, as evidenced by periods of rapid movements of nose and whiskers;

Grooming: Time spent by the animal in self-care activities, which include rubbing, licking, scratching or biting parts of its own body for cleaning;

Inactive: Total time during which the animal is not involved in any salient activity or movement but only in resting or basal activity. Its eyes may be open or closed but the rat does not move the head or the ears in orienting responses nor is sniffing;

Rearing: Number of times that the animal raises both forelimbs from the floor, keeping them in the air or standing against a wall, but not using them for other activity like grooming;

Forelimb stepping: Number of times that the animal raises the right hand from the floor, whether for body displacement or not, except when done for grooming;

Hindlimb stepping: Number of times that the animal raises the right foot from the floor, whether for body displacement or not, except when done for grooming.

\subsection{Procedures}

The animals were identified by a number printed at the tail base. Of each cage, one rat was randomly assigned to vehicle group and the other to quinpirole treatment group. All the procedures were carried out under quiet conditions in a testing room adjacent to the rat stock room. The behavioral tests were started at the 3 rd hour of the light period. After each behavioral recording, the animals were immediately returned to their home cages in the maintenance racks with food and water ad lib. Rats were habituated daily to the experimental procedure for 3 days previous to the tests by placing them undisturbed in the testing boxes for 15 minutes. 
The treatment consisted in a single intraperitoneal injection of $1 \mathrm{ml}$ of $\mathrm{NaCl}$ isotonic solution per $\mathrm{kg}$ of body weight containing $1 \mathrm{mg} / \mathrm{ml}(-)$-quinpirole hydrochloride (Sigma-Aldrich ref. Q102) or nothing else in vehicleinjected group. Injections and behavioral recordings were performed under a fixed time schedule and both animals in a cag e r eceived the treatment at the same time and $w$ ere recorded simultaneously starting at p recise times. Ten minutes before each recording, the rats were placed undisturbed in their respective testing boxes to habituate. Testing boxes consisted in transparent square cages $(17 \times 22 \times 14 \mathrm{~cm})$ with a grid bottom made of 7 $\mathrm{mm}$ wire mesh (to prevent accumulation of urine or feces).

Animals were video recorded with a high definition web camera (Logitech HD Webcam C270) at 30 frames/ second downloading to a computer. The camera was placed at a distance of $56 \mathrm{~cm}$ from the front of the testing cage and was elevated $30 \mathrm{~cm}$ above the level of the cage floor to have a complete vision of the whole cubicle. A slightly angled mirror was placed opposed to the camera so that recordings contained no hidden spots and all parts of the animal were visible. No additional illumination was required besides ambient light since the video recording provided sufficient picture quality and both direct and mirror images were on focus. The recording lasted 120 seconds, after which the animals were immediately returned to their home cages. Video analysis was carried out after all animals had been recorded. The analysis was performed by scoring one behavior and one animal at a time by repeated playing of video recordings. A hand-held digital chronometer was used for time scoring and a tally counter was used for scoring events.

Statistical analyses were performed with the help of GraphPad Prism software (v. 4.03) and consisted in twoway ANOVA of repeated measures with Bonferroni's post-test. Differences were considered significant when $p$ $<0.05$. No value was considered outlier.

\section{Results}

Six different behaviors were scored in rats during $120 \mathrm{~s}$ periods at different time points after intraperitoneal injection of $1 \mathrm{mg} / \mathrm{kg}$ quinpirole or vehicle (Figure 1). Each behavior followed a characteristic time course of outcome response in the present experimental conditions. As a general trend, in control (vehicle-injected) animals, highest level of activity was observed at the $15 \mathrm{~min}$ time point, decreasing afterwards except for a mild rise of activity at the $24 \mathrm{~h}$ time point. Quinpirole administration changed that time course in some behaviors. Forelimb stepping scoring was the most sensitive outcome measurement to show the pharmacological activity of quinpirole. After injection of the D2R agonist, forelimb steps increased significantly at $15 \mathrm{~min}(p<0.01)$ and this effect was still observed after $24 \mathrm{~h}(p<0.05)$. Time spent sniffing was also a reliable indicator of the behavioral changes produced by quinpirole, increasing significantly already by $15 \mathrm{~min}(p<0.05)$; at 90 and $180 \mathrm{~min}$ time points quinpirole-injected rats performed continuous sniffing. However, by $360 \mathrm{~min}$ this behavioral score was not sensitive to show differences with the present number of experimental animals. Hindlimb stepping was also markedly increased and time spent inactive was practically null in quinpirole-injected rats at 90 a nd $180 \mathrm{~min}$, but these behavioral scores were not statistically different earlier or after $360 \mathrm{~min}$.

Rearing a nd grooming $\mathrm{s}$ cores $\mathrm{y}$ ielded $\mathrm{l}$ ess consistent $\mathrm{m}$ easurements of $\mathrm{r}$ at a ctivity a nd $\mathrm{w}$ ere $\mathrm{n}$ ot $\mathrm{s}$ ensitive enough to show the behavioral effect of quinpirole in the present experimental conditions (not significant ANOVA test for time, treatment or interaction).

\section{Discussion}

Based on previous observations, we devised a test that could provide easy, fast, reproducible and inexpensive measurements of the effects of quinpirole on spontaneous activity of rats. Using purposely reduced numbers of experimental animals (10 rats per experimental group) neurological actions of $\mathrm{D} 2 \mathrm{R}$ agonist can be behaviorally revealed by this methodology. The behavioral manifestations of quinpirole are context-dependent [5] [10] so rats in their home cage, accompanied by other familiar rats, may not show overt signs of sensitization, stereotypy or compulsive checking after quinpirole administration. The action of placing the animals unaccompanied in the testing cage, even when such stimulus is not novel, triggers the display of a panel of characteristic behaviors that can be measured. The 10-minute period in the testing cage previous to the 2 -minute recording is essential for development of such behavioral manifestations, so the timing needs to be rigorously kept for reproducibility of results. The methodology, or adaptations of it, could be similarly used for testing the time course of the effects of dopaminergic drugs with precision of less than one hour and can be used likewise for testing differences of spontaneous a ctivity in c hronic treatments or interactions w ith other d rugs, like c lomipramine [11], provided that the testing schedules are strictly fixed. 

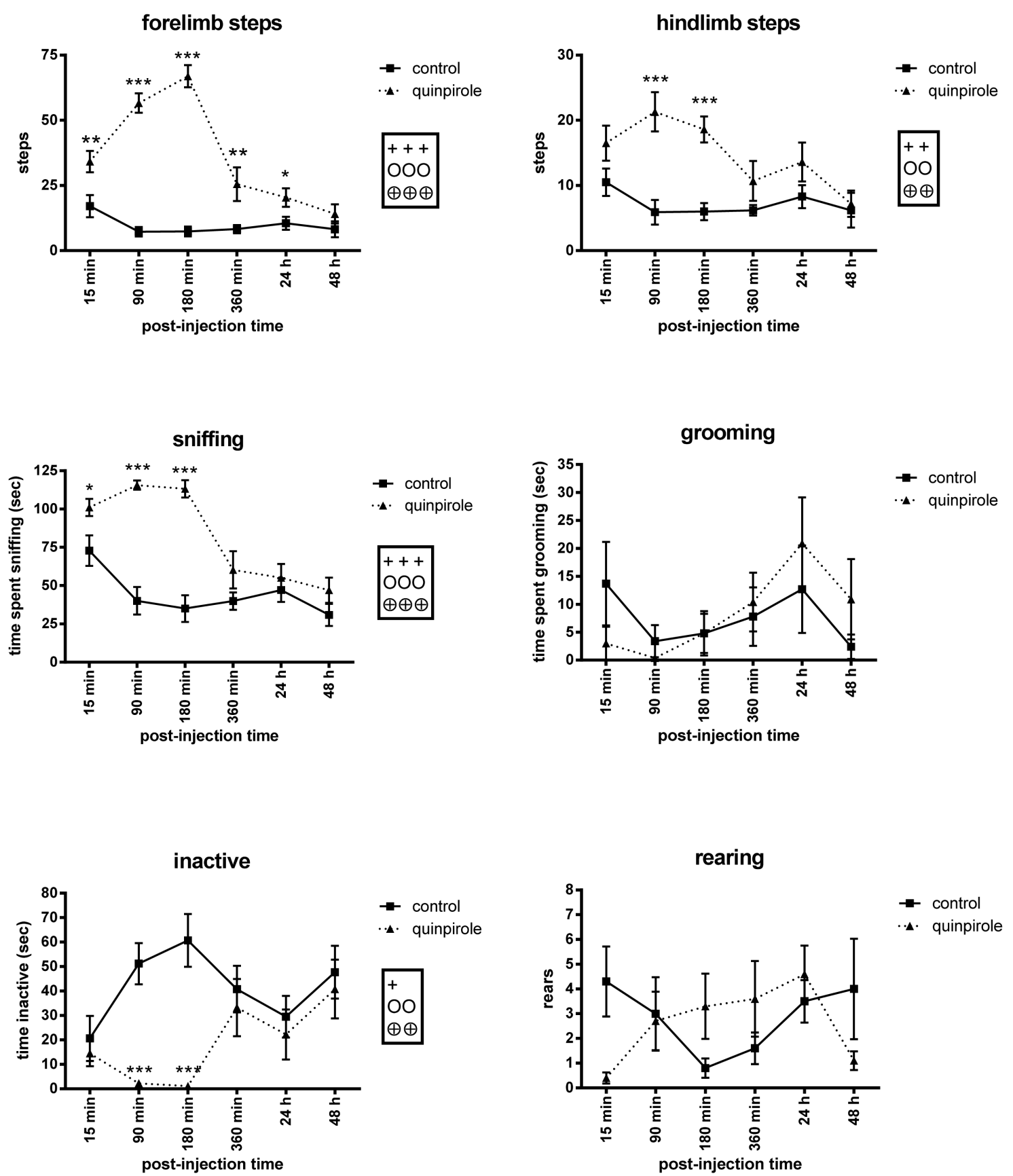

Figure 1. Scores of 6 spontaneous behaviors in $120 \mathrm{sec}$ recordings. Rats were placed undisturbed for $10 \mathrm{~min}$ in the testing cages and video-recorded for the following $2 \mathrm{~min}$. Values represent mean $\pm \operatorname{SEM}(\mathrm{n}=10)$. Dotted-line follows the time course of scores in $1 \mathrm{mg} / \mathrm{kg}$ quinpirole-injected rats and continuous line, that of vehicle-injected (control) rats. Symbols: significances of two-way ANOVA for time $(+)$, column $(O)$ or interaction $(\oplus)$ and $t$ test $\left(^{*}\right)$. Statistical significance: one symbol: $p<0.05$; two symbols: $p<0.01$; three symbols: $p<0.001$.

Most previous s tudies have measured locomotor a ctivity to t est the dose-response and time-course of the pharmacological action of quinpirole [7] [12], while a few have used open field checking activity [13], operant conditioning [14] or spontaneous activities like sniffing, rearing, grooming [12] or yawning [15]. These tests, however, lack time precision since they measure be havior a long extended periods and thus stimulus no velty, which is relevant for context-dependent manifestations, is gradually lost.

The present report is meant to propose a new simple method to assess the behavioral activity of D2R agonists. 
It remains to be validated by u sing other D2 - or D3 -preferring a gonists as well as by low doses of a gonists which would preferentially act on presynaptic autoreceptors [2]. On the other hand, this method has been developed using S prague-Dawley rats, which is the strain that has be en us ed more often for studying the psychopharmacology of D2R agonists. It remains to be tested if these behavioral responses to quinpirole treatment are kept in other rat strains, like Wistar or Long-Evans.

Of the six signs of basal activity that have been scored in the present study, the behavior here defined as "forelimb stepping" appears to be the most sensitive detector of the effects of quinpirole, being able to reveal these effects as early as $15 \mathrm{~min}$ and as late as $24 \mathrm{~h}$ after a single $1 \mathrm{mg} / \mathrm{kg}$ dose. We have not found reports in the literature showing behavioral effects of acute quinpirole after $24 \mathrm{~h}$, so it appears that recording of forelimb stepping provides a highly sensitive test on the action of D2R agonists on basal activity. At 90 and 180 min time points after the quinpirole injection, rats displayed continuous sniffing accompanied by frequent limb movement. By 6 $\mathrm{h}$ quinpirole-treated rats showed some inactive periods and by $24 \mathrm{~h}$ only forelimb movements remained significantly raised. No difference in spontaneous behavior was detected by $48 \mathrm{~h}$. This notwithstanding, the neurological activity of quinpirole persists at that time, since we have observed that a single injection of $1 \mathrm{mg} / \mathrm{kg}$ quinpirole inhibits tactile allodynia for longer than $48 \mathrm{~h}$ in rats subjected to chronic constriction injury of the sciatic nerve [16], which would suggest that analgesia by quinpirole can be achieved without accompanying alterations in basal activity.

In conclusion, the simple behavioral procedure here described provides a sensitive test to evaluate the time course of the effects of D2R agonists on rat basal activity.

\section{Acknowledgements}

I thank Mari Paz Muñoz for technical help and C. Correa and A.I. Ortiz for veterinarian assistance. The present work was supported by Fondo de Investigaciones Sanitarias PI05/1324. There are no conflicts of interests.

\section{References}

[1] Schmitz, Y., B enoit-Marand, M., Gonon, F. and Sulzer, D. (2003) Presynaptic Regulation of Dopaminergic N eurotransmission. Journal of Neurochemistry, 87, 273-289. http://dx.doi.org/10.1046/j.1471-4159.2003.02050.x

[2] Usiello, A., Baik, J.H., Rouge-Pont, F., Picetti, R., Dierich, A., LeMeur, M., Piazza, P.V. and Borrelli, E. (2000) Distinct Functions of the two Isoforms of Dopamine D2 Receptors. Nature, 408, 199-203. http://dx.doi.org/10.1038/35041572

[3] Ferguson, S.S.G. (2001) Evolving Concepts in G Protein-Coupled Receptor Endocytosis: The Role in Receptor Desensitization and Signaling. Pharmacological Reviews, 53, 1-24.

[4] Mattingly, B.A., Gotsick, J.E. and S alamanca, K. (1988) L atent Sensitization to A pomorphine F ollowing Re peated Low Doses. Behavioral Neuroscience, 102, 553-558. http://dx.doi.org/10.1037/0735-7044.102.4.553

[5] Szumlinski, K.K., Allan, M., Talangbayan, H., Tracey, A. and Szechtman, H. (1997) Locomotor Sensitization to Quinpirole: Environment-Modulated Increase in Efficacy and Context-Dependent Increase in Potency. Psychopharmacology (Berlin), 134, 193-200. http://dx.doi.org/10.1007/s002130050442

[6] Chang, W.L., Breier, M.R., Yang, A. and Swerdlow, N.R. (2011) Disparate Effects of Pramipexole on Locomotor Activity and Sensorimotor Gating in Sprague-Dawley Rats. Pharmacology Biochemistry and Behavior, 99, 634-638. http://dx.doi.org/10.1016/j.pbb.2011.06.002

[7] Eilam, D. and Szechtman, H. (1989) Biphasic Effect of D-2 Agonist Quinpirole on Locomotion and Movements. European Journal of Pharmacology, 161, 151-157. http://dx.doi.org/10.1016/0014-2999(89)90837-6

[8] Berger, A.K., Green, T., Siegel, S.J., Nestler, E.J. and Hammer Jr., R.P. (2011) cAMP Response Element Binding Protein P hosphorylation in N ucleus A ccumbens U nderlies S ustained Re covery of S ensorimotor G ating F ollowing Re peated D(2)-Like Receptor Agonist Treatment in Rats. Biological Psychiatry, 69, 288-294. http://dx.doi.org/10.1016/j.biopsych.2010.08.032

[9] Zhou, L.W., Qin, Z.H. and Weiss, B. (1991) D ownregulation of Stereotyped Behavior and Production of Latent Locomotor Behaviors in Mice Treated Continuously with Quinpirole. Neuropsychopharmacology, 4, 47-55.

[10] Szechtman, H., Talangbayan, H. and Eilam, D. (1993) Environmental and Behavioral Components of Sensitization Induced by the Dopamine Agonist Quinpirole. Behavioural Pharmacology, 4, 405-410. http://dx.doi.org/10.1097/00008877-199308000-00014

[11] Eilam, D. and Szechtman, H. (2005) Psychostimulant-Induced Behavior as an Animal Model of Obsessive-Compulsive Disorder: An Ethological Approach to the Form of Compulsive Rituals. CNS Spectrums, 10, 191-202. 
[12] Horvitz, J.C., Williams, G. and Joy, R. (2001) Time-Dependent Actions of D2 Family Agonist Quinpirole on Spontaneous Behavior in the Rat: Dissociation between Sniffing and Locomotion. Psychopharmacology (Berlin), 154, 350 355. http://dx.doi.org/10.1007/s002130000677

[13] Szechtman, H., Eckert, M.J., Tse, W.S., B oersma, J.T., B onura, C.A., McClelland, J.Z., Culver, K.E. and Eilam, D. (2001) Compulsive Checking Behavior of Q uinpirole-Sensitized Rats as an Animal Model of Obsessive-Compulsive Disorder (OCD): Form and Control. BMC Neuroscience, 2, 4. http://dx.doi.org/10.1186/1471-2202-2-4

[14] Kurylo, D.D. (2004) Effects of Quinpirole on Operant Conditioning: Perseveration of Behavioral Components. Behavioral Brain Research, 155, 117-124. http://dx.doi.org/10.1016/j.bbr.2004.04.015

[15] Li, S.M., Collins, G.T., Paul, N.M., Grundt, P., N ewman, A.H., Xu, M., Grandy, D.K., W oods, J.H. and Katz, J.L. (2010) Y awning and Locomotor Behavior Induc ed by Dopamine Receptor Agonists in Mice and Rats. Behavioural Pharmacology, 21, 171-181. http://dx.doi.org/10.1097/FBP.0b013e32833a5c68

[16] Cobacho, N., De la Calle, J.L. and Paíno, C.L. (2014) Dopaminergic Modulation of N europathic Pain: A nalgesia in Rats by a D2-Type Receptor Agonist. Brain Research Bulletin, in Press. http://dx.doi.org/10.1016/j.brainresbull.2014.06.003 
Scientific Research Publishing (SCIRP) is one of the largest Open Access journal publishers. It is currently publishing more than 200 open access, online, peer-reviewed journals covering a wide range of academic disciplines. SCIRP serves the worldwide academic communities and contributes to the progress and application of science with its publication.

Other selected journals from SCIRP are listed as below. Submit your manuscript to us via either submit@scirp.org or Online Submission Portal.
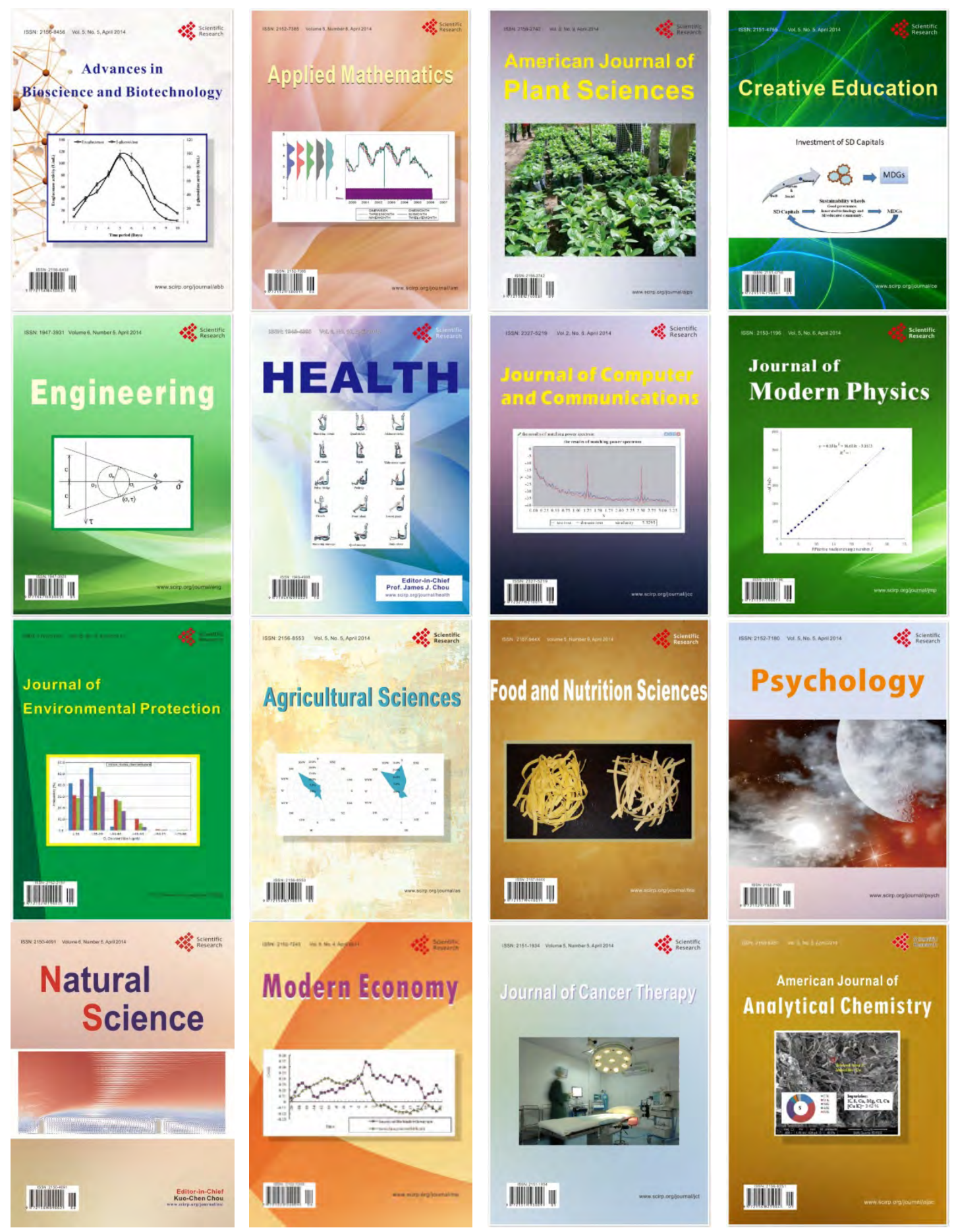

Analytical Chemistry

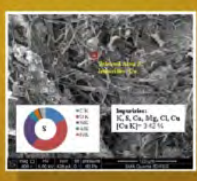

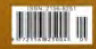

